\title{
THE IMPLEMENTATION OF GROUP INVESTIGATION MODEL (GIM) TO ENHANCE STUDENTS' CRITICAL THINKING SKILL IN EDUCATIONAL PROGRAM EVALUATION CLASS
}

\author{
Connie Chairunnisa \\ Graduate School, University of Muhammadiyah Prof Dr. HAMKA, Jakarta, Indonesia \\ zusconnie@uhamka.ac.id
}

\begin{abstract}
The purpose of this study is to gain insight on: 1) The Implementation of group investigation model (GIM) in increasing student conceptual achievement, 2) How GIM may improve student's critical thinking skill, and finally 3) the study addresses some challenges in GIM implementation. To achieve these purposes, classroom action research (CAR) was employed to investigate 19 students taking Educational Program Evaluation module in the second semester 2015/2016 at the Department of Educational Administration in University of Muhammadiyah Prof. Dr Hamka, Jakarta, Indonesia. Data were collected through test, observation, interview, questionnaires and documents. The study found that 1) the practice of GIM improve students' achievement on the conceptual domain; 2) GIM enhances students' critical thinking skill; 3) Some challenges identified during GIM implementation include teacher's teaching orientation and lack of students' discipline in completing assignments.
\end{abstract}

Keywords: Group Investigation Model (GIM); conceptual achievement; educational program evaluation; critical thinking; teaching orientation.

\section{Introduction}

It is apparent that studying in a university differs from studying in secondary school. At the university level, students are given more freedom to decide on their own learning. Many universities in Indonesia have employed varied learning systems which provide students with varied autonomous activities which enable them to achieve a certain level of maturity and independent individuals. Within this learning system, development of students' critical thinking is a priority in their curriculum and teaching and learning practices.

In many countries, particularly in western countries, critical thinking skill has become one of higher educational goals (for example, see Ilyas, 2015, 2016). The development of critical thinking skills in the university has been an important competency in that it promotes students' construction of knowledge. It is thus students should be engaged in the activities that facilitate critical thinking. Also in the context of Indonesia, critical thinking has been considered as one of the essential components of the competency-based curriculum (PuskurDepdiknas, 2002). More interestingly, the late Regulation Number 17 of 2010 has clearly stated that critical thinking is one of the educational objectives in Indonesia (Ilyas, 2016). The practice of teaching and learning in Indonesian classrooms is not only aimed at enabling students to achieve a certain level of knowledge construction, but more importantly, it should enhance students' critical thinking ability. Unfortunately, according to Ilyas (2016), many of Indonesian teachers have not yet had knowledge about critical thinking and its classroom implementation. This little knowledge accordingly seems to be the reason why teachers in Indonesia do not include critical thinking aspect in their classroom instruction.

The development of students' critical thinking ability through classroom teaching and learning activities is not an instant task. It requires commitment, efforts and, of course, time. More importantly, educational institutions, as well as teachers who are a commitment to promoting critical thinking in classroom practice, should deeply understand the nature of critical thinking and how it can be implemented in their classroom context. This may help them encounter issues which emerge during the implementation of critical thinking in classrooms.

Brooks \& Brooks (1993) have identified a crucial problem faced by education across nations; that is how to build an understanding and an empowerment of student critical thinking skill through a learning process in classrooms. In learning, comprehension and critical thinking skill are far more important than learning achievement as measured by tests that are emphasising students' memorization skill (Brooks \& Brooks, 1993). In fact, current learning praxis keeps on focusing on information transfer paradigm which involves lower learning level - memorising (Joni, 2005). This current praxis, in fact, may reason why several modes of learning in many educational institutions like school and university remain conventional and they still consider the students and lecturers respectively as a learning object and subject classroom teaching and learning practices. Accordingly, by observing on how educational program evaluation class took place in Indonesia, it seems that students are rarely to be posed with critical questions or given opportunities to 
discuss everything written in a lesson plan. Limited time and inductive teaching and learning environment have been the factors that constrain teachers' promotion of critical-thinking based activity in classrooms.

A body of literature has shown the benefits of cooperative learning, among others Hsiung (2012), Laal and Ghodsi (2012), Lin (2015), Rennie and Morrison (2013), and Tsay and Brady (2012). Tsay and Brady (2012), for example, demonstrate that cooperative learning provides students with the opportunity to work with others, sharing ideas and facilitate mutual interactions amongst students themselves. These benefits accordingly promote positive construction of knowledge and, more than that, they suggest positive relationships between students' academic achievement and their learning attitudes. Despite these benefits, cooperative learning, which base its principles on active learning, has not been widely practised in Indonesian classrooms particularly in the higher education context. Prior to the present study, I had observed that many of educational program evaluation classroom instructions in my university particularly are delivered through the use of the conventional method of teaching and such a condition seems to provide a little opportunity for students to discuss the subject matter. This indicates that such a classroom condition does not seem to offer educational managers as well as teachers opportunities to shape their professional competence.

Group investigation model (hereafter GIM) is a model of cooperative learning. Slavin (1995) suggests that GIM is an appropriate model for the type of reintegration project because it includes information gathering, synthesis and problem solving. Interestingly, GIM suggests learning motivation for the students and gives an opportunity for classroom discussion. Thus, GIM is viewed as an alternative to promote critical thinking in classrooms. This present study is conducted to examine the implementation of GIM in the Department of Educational Administration in University of Muhammadiyah Prof. Dr Hamka, Jakarta, Indonesia. Specifically, the present study attempts to answer the following research questions:

1) Does the application of GIM increase students' understanding of the concept of a subject and improve their critical thinking skill?

2) What are challenges that teachers encounter when practising GIM in Educational Program Evaluation Classrooms?

\section{Literature review}

According to Thanthowi $(1993,2010)$, critical thinking refers to a process of finding meaningful relation amongst components of knowledge. Syah (2002, p. 119) defined associative thinking as the process of associating one thing to another and making the relationship between stimuli and responses. Liang Gie (2000, p. 13) defines thinking as a single spiritual activity which manifests in three different domains: 1) clear thinking, meaning that mental virtues capable of clearly grasping varieties of problems and understanding several aspects of knowledge. A person who has clear thinking seems to depict a smart mind. 2) Keen thinking is a mental activity that indicates the ability to see differences, disharmony or subtle differences and able to come to a right conclusion without being trapped by false thinking. 3) Agile thinking is a mental activity that is flexible, showing the ability to prompt various ideas from time to time which are useful in problems solving.

Louis et al. (1968, p. 48) state that thinking is an activity created by concept or skill identification, it is expected that when students are taught to express their ideas within a framework of higher order skill. Critical thinking is a manifestation of learning behaviour especially related to problem-solving (Syah, 2002, p. 120). In general, a student who has rational thinking uses principles and basics of good and bad in answering how and why. On the whole, there are two types of thinking such as caustic thinking and realistic thinking. The first type may be categorised to daydreaming, and the second may be called as resounding which is related to real world. There are three types of realistic thinking: deductive, inductive and evaluative. Evaluative thinking is critical thinking, evaluating ideas whether they are good or bad, appropriate or not.

Critical thinking is an evaluative thinking which can sense the gap between facts and what should be (das sein and das sollen), inferring to what is ideal; capable of analysing and evaluating and able to find out problem-solving strategies.

The concept of learning readiness, this concept contains at least two implications: (1) Curriculum should be organised in such a way to meet the demand of individual real life rather than fulfil institution's mission. (2) The concept of readiness which is being developed should be considered in terms of a student group. Some learning theories mention that homogenous grouping is more effective but the other theories believe that heterogeneous grouping is preferable. The above mentioned basic assumption becomes an inspiration in the learning process which must be accepted by university students, both inside classroom and outside classroom, such as in a library, laboratory or in the field. 
In the framework of getting a complete picture of GIM application to enhance students' critical thinking skill, there are three components needed for the object evaluation, those are learning program, program implementation, and outcome. The outcome can be both short term and long term. The outcome of learning program is not less important than the output, because the outcome describes the extent to which students are able to translate the learned competence in the classroom into the real world for solving societal problems.

GIM has been used in various studies at different age levels. Basically, this model is designed to guide students to define problems and to explore various sub-problems. Then, they collect relevant data, develop and test hypotheses. GIM has three main components: inquiry, knowledge, and group dynamics - the dynamic of the learning group. This research is a dynamic process of students' response to problems and solutions. Knowledge is students' learning experiences acquired directly or indirectly. The group dynamic is a condition in which a group of students interact with each other, discuss various ideas, and exchange experiences through the process of discussion. Slavin (1995) perceives GIM as a learning activity which is an ideal model to improve students' communication and social skills. In addition, the model is suitable for studies or projects that require group activities.

\section{Methodology}

As mentioned earlier, the present study was conducted to examine the implementation of GIM in the Department of Educational Administration in University of Muhammadiyah Prof. Dr Hamka, Jakarta, Indonesia. A classroom action research was employed to achieve this objective. In this type of research, I adopted a classroom action research design proposed by Lewin (1990), specifically the model which promoted student's critical thinking skill. Lewin's (1990) model of classroom action research employed four steps: planning, acting, observing and reflecting.

The strategy of cooperative learning in classroom employed GIM and this was based on John Dewey's education learning philosophy (Slavin, 1995). Dewey's philosophy suggests that classroom is a mirror of society and functions as real-world learning laboratory which is intended to study individual and social problems.

The study involved 19 students, consisting of 5 males and 14 female students. Male-female were unequal in proportion but they are homogeneous in academic capabilities in term of group work. The 19 students were taking an educational program evaluation mode which was one of the important course works because it needs a lot of logic to understand the subject.

\section{Classroom procedure and findings}

As discussed in the previous section, the study employed an action research design proposed by Lewin (1990) and it was performed under a research procedure: preconditioning, cycle-1, cycle-2 and finally cycle-3. The detail of each stage is presented below:

\section{Preconditioning}

The precondition stage aimed at providing students with a conducive learning environment which may motivate them to learn materials from the educational program evaluation module. In this stage, first, I informed the students about strategies they needed to undertake during the session, that was the GIM. This step is very important since the students of this class are not familiar with the model. It was, therefore, during the first up to the third session, I informed and explained the students about the lesson plan, classroom interaction, GIM concept and the scope of the study. I also trained the students about GIM and how to practice it in the classroom. This happened in the third session. In the session, students were divided into six groups to conduct group presentation based on agreed topics. Group One: Objective Oriented Model; Group Two: Goal-Free Evaluation Model; Group Three: Formative-Summative Model; Group Four: Responsive Evaluative Model; Group Five: CIPP Model; and Group Six: Adversary Model.

2. Implementation of cycle-1 and the findings

The cycle 1 lasted within one session. It focused on discussion paper one with the topic of objective oriented model. In this session, students presented their papers which were made by group one. The paper was primarily based upon literature review relevant to objective oriented model. The researcher gave necessary comments during the group discussion, made rearrangement and requested the students to make the conclusion of their discussion. The formative test was conducted after group discussion. In addition, student self-assessment was performed to measure students' understanding about group paper. Findings from the cycle-1 were as below:

a) Students' understanding of the concept in Educational Program Evaluation reflects how deep they can understand the concept of this course. Objective Oriented Evaluation of cycle-1 contains questions to measure their understanding of the concept of related issues. The result from the formative test showed that the highest 
score is 7.8, the lowest score is 5.3 and the mean score is 6.6. The result of student self-assessment showed that four members of the group- 1 achieved a mean score of 48.9 indicating medium level.

b) Students' critical thinking ability

In this activity, the researcher investigated students' critical thinking skill by assessing their analyses, syntheses and evaluation capabilities. Such an investigation was focused on students' questions, presentation and discussion. Most of the questions went on analytical aspects which indicate that students possessed a very low level of evaluation skill. This happened because students seemed to have a little knowledge about topics being discussed. Students felt that topics in the module were new for them. This accordingly limits students from asking critical questions during the discussions. For example, many of which were mainly asking for clarification rather than deep analysis of particular issues.

In addition, the students who were not presenting in the classroom were also assessed for their critical thinking ability. It was done by distributing self-evaluation form to 15 students in the classroom. Students' self-evaluation was employed to provide more detailed information relevant to students' critical thinking ability and it supported my observation during the study. The analysis of students' self-evaluation revealed that the capability of students in posing questions: $54.5 \%$ of them scored in good comprehension level. Furthermore, it was reported that students' ability to answer questions fell into the category of "being able to understand" and "ability to synthesise a discussion" (63.6\%); 54.5\% of the students were able to comprehend and synthesise. In general, $57.5 \%$ of the students still on the position of comprehension level indicating that students did not possess enough critical thinking skill.

3. Implementation of cycle-2 and the findings

The cycle- 2 involved three activities. First, students were asked to study the learning materials related to the evaluation of management oriented through goal-free evaluation. Second, students were put into groups and each group made a small discussion. Third, each of the presenters was asked to make a presentation based on their understanding of the materials. At the end of the discussion, I provided clarification, explained to the students the key issues of their presentation and finally, I asked students to make a conclusion.

In the cycle-2, I developed a formative test to measure students' level of conceptual understanding. The test was also aimed to assess students' mastery of the subject taught. The test was distributed to the students after the students completed group discussion and after I gave an explanation of the topic. The formative test score showed the following result: the highest 8.3, the lowest 5.7 and the mean totalled of 7.0 which was good. Compared to the findings in the cycle-1, students' understanding on the subject generally improved. The increase of the mean scores at the cycle-2 indicated such an improvement.

In the cycle-2, I distributed self-evaluation form to the students to support my observation. The result of students' group evaluation showed that students' level of comprehension on subject matter increased as indicated by the increase of the mean score. Students' ability in questioning was also enhanced in cycle-2. For example, there were 7 cases in cycle-1 and 9 cases in cycle-2. Students' motivation to participate actively in the discussion and additional individual assignment where students were asked to review related topics from several resources other than textbook before the class begun were factors that explain such an improvement.

Similar to the cycle-1, I also gave the students self-evaluation form to examine students' ability of critical thinking. The students who were not presenting in the classroom were also assessed for their critical thinking ability. In this cycle-2, 19 students filled the forms. Within the form, students reflected their experience during the classroom session. The analysis of students' self-evaluation form suggested that $66.7 \%$ of the students could pose questions during the discussion and 50\% could make a conclusion and 58\% could comprehend. In general, $38,9 \%$ of students still were in the level of comprehension.

4. Implementation of cycle-3 and the findings

This cycle 3 was performed to facilitate students express conceptual understanding of the topic. The formative test was given after the students finished the group discussion. Learning enrichment was also conducted by the teacher to follow up the formative test result. In measuring students' critical thinking on educational program evaluation class, the researcher conducted an observation focusing on analytical, synthesis, and evaluation.

In general, cycle-3 was the continuation of cycle-1 and cycle-2; however, the discussion of group work was expanded to provide me with more information of students' posing the questions. Specifically, the group work involved an extensive discussion within which the students were given more opportunities to understand teaching materials and doing their critical analysis. The classroom procedure of cycle-3 was described below:

a) Conditioning. In this stage, students were assigned to study the materials that contained both formative and summative evaluation in order to enlighten the situation. 
b) Presentation and clarification. In this stage, students presented their topic and at the end of the discussion, I gave the students explanation relevant to their presentation and asked them to make a conclusion. It is important to note that each of the presenters was asked to present his or her topics by exploring the materials based on their own understanding.

Findings from cycle-3 showed that students' understanding of the concept of educational program evaluation improved. The result of the test showed that students' understanding of the concept was as high as 8.7 and the lowest was 6.5 and the mean score was 7.6 which was good. Similar to the cycle-1 and 2, I distributed self-evaluation to the students to measure their conceptual understanding and to provide additional information to my observation. The form was distributed to the students after their group work presentation. The result of students' self-evaluation found at the average score of 53.3 (medium) which indicated that students' ability in posing ideas and questions improved. More importantly, I observed that the students were more active in cycle-3. This happened due to students' motivation to participate in the discussion and to read more books other than textbooks before they attend the class. This also affected on their achievement in their individual assignment.

It was also observed that students' critical thinking skills improved in cycle-3. For example, students now were able to classify particular problems into their components, synthesise, compare between different values and ideas by using standard. Most students (83.3\%) are good in comprehension of concepts. The ability of students to provide answers and summary remained were also good (66.7\%). $58.3 \%$ of students were good in synthesising conclusion. On the whole students' critical thinking was in a good comprehension category $(38.9 \%)$.

\section{Discussion}

This section will discuss the findings from the research cycle 1, 2 and 3. Specifically, it addresses the two research questions of the present study:

Research question 1: Does the application of GIM increase students' understanding of the concept of a subject and improve their critical thinking skill?

The application of GIM helps students improve their ability to think critically. It was found in the study that students' critical thinking ability improves in cycle-2 and in cycle-3. Cycle-1, 2, and 3 provided a series of activities that facilitated students' critical thinking skill, mainly the opportunity to express their ideas and pose questions. It was found in the three cycles of the study that students' discussion during group presentation to shape their ability to think criticality. The essence of GIM is particularly to make the students active in completing their assignments, analysis, course evaluation. This was done through student assignment and formative test. It is important to note here that the role of a lecturer included facilitating, motivating and organising students' group learning activity.

However, the study highlights several issues. First, based upon the observation and student selfevaluation in the cycle-1 and cycle- 2 reflection stages, students' mastery of the related subject still needed an improvement. The evidence of this argument was based on the result of the formative test showing that some students got scores under 5.9 and students' self-evaluation on paper of group work resulted lower than 5.9. Also, the finding showed that students needed to improve their ability to think critically, especially on the aspect of students' ability to analyse, synthesise, and evaluate ideas. It was also reported that the students still possessed low argumentation skill. This might be the reason why students were not good at doing critical analysis. Students' lack of reading literature was also the reason for this low ability in critical analysis. The findings of the study showed that paperwork made by students had little of support from the body of literature. Additionally, students did not seem well prepared for their presentation. This poor reading and little preparation seem to have made students unable to respond to the questions satisfactorily.

Research question 2: What are the challenges that teachers encounter when practising GIM in Educational Program Evaluation Classrooms?

In the present study, the implementation of GIM encountered two challenges such as academic viewpoint and non-academic viewpoint. In the academic point of view, school culture and learning method are still focused on the lecturer, not on the students. Accordingly, students did not seem to be motivated and were not actively involved in the process of learning. In addition, during the discussion, there was no clear division of roles between moderator and students. This problem constrained students from understanding and thinking critically. To solve this problem discussion guideline and manual for academic writing, therefore, should be provided. Furthermore, in the non-academic point of view, discipline and responsibility have been part of students' main issues that implied on the low process of learning. To address this issue, students and lecturer then need to sign a kind of learning contract. 


\section{Conclusions and recommendations}

To sum up, the implementation of Group Investigation Model in Education Program Evaluation class can increase students' critical thinking skill. This finding is supported by observation and student selfevaluation data as indicated by increasing scores all through cycles. In addition, the implementation of GIM can improve students' conceptual comprehension. The findings of the study showed that students' mean scores improved at the formative test. Two main challenges in the implementation of GIM include the academic and non-academic aspects. Thus, the study offers three recommendations: first, more preparations are needed before implementation of GIM. The lesson plan, course materials, assignments and evaluation system should promote active learning. Second, the implementation requires guidance in order to fully support Group Investigation Learning, and finally, all the preconditions should be established before implementing GIM.

\section{References:}

Asmani, J.M. (2011). Penelitian tindakan kelas. Yogyakarta: Laksana.

Arikunto, Suharsimi. (2006). Penelitian tindakan kelas. Jakarta: Bumi Aksara.

Brooks, J.G., \& Brooks, M. G. (1993). In search of understanding the case for constructivist classrooms. Alexandria. VA: Association for Supervision and Curriculum Development.

Depdiknas. (2002). Pendekatan kontekstual. Jakarta: Pusat Kurikulum Depdiknas.

Herrmann, K. J. (2013). The impact of cooperative learning on student engagement: Results from an intervention. Active Learning in Higher Education, 14(3), 175-187. https://doi.org/10.1177/1469787413498035

Hsiung, C. M. (2012). The effectiveness of cooperative learning. Journal of Engineering Education, 101(1), 119. https://doi.org/10.1002/j.2168-9830.2012.tb00044.x

Ilyas, H.P. (2015). Critical thinking: Its representation in Indonesian ELT textbooks and education. Unpublished doctoral thesis, University of York, UK.

Ilyas, H.P. (2016). Infusing critical thinking into English course books. Journal of ELT Research, 1(1), 113-134.

Lin, L. (2015). Investigating Chinese HE EFL classrooms: Using collaborative learning to enhance learning. Springer.

Laal, M., \& Ghodsi, S. M. (2012). Benefits of collaborative learning. Procedia-Social and Behavioral Sciences, 31, $486-490$. https://doi.org/10.1016/j.sbspro.2011.12.091

Raths, L. E., Wasserman, S., Jonas, A., \& Rothstein, A. (1986). Teaching for thinking. New York: Teachers College.

Rennie, F., \& Morrison, T. (2013). E-learning and social networking handbook: Resources for higher education. Routledge. https://doi.org/10.4324/9780203120279

Joni, R.T. (2006). Pembelajaran yang mendidik: Artikulasi konseptual, terapan konsektual, dan verifikasi empirik. Malang: PPS UM.

Slavin, R.E. (1995). Cooperative learning: Theory, research, and practice. Second Edition. Massachusetts: Allyn and Bacon Publishers.

Sanjaya, W. (2009). Strategi pembelajaran berorientasi standar proses pendidikan. Jakarta.

Thanthowi Achmad. (1993). Pskilogi pendidikan. Bandung: Angkasa.

Thanthowi Achmad. (2010). Pskilogi pendidikan. Bandung: Angkasa.

The Liang Gie (2000). Belajar Yang Baik Bagi Mahasiswa. Yogyakarta: Gajah Mada Univ. Press.

Tsay, M., \& Brady, M. (2012). A case study of cooperative learning and communication pedagogy: Does working in teams make a difference? Journal of the Scholarship of Teaching and Learning, 10(2), 78-89. 